\title{
Blogging in the Political Science Classroom
}

Christopher N. Lawrence, Texas A\&M International University

Michelle L. Dion, McMaster University

ABSTRACT Weblogs (or blogs), as a form of communication on the Internet, have recently risen in prominence but may be poorly understood by both faculty and students. This article explains how blogs differ from other online communication tools and how political science faculty can make use of blogs in their classes. The focus is on using blogs as part of class assignments to reinforce important skills, including critical thinking, political engagement, and essay writing. We also discuss existing academic and professional blogs that may be models for student blogging in political science.

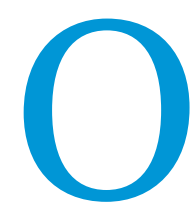

ver the last decade, information technology (IT) innovations, including in-class presentation technologies, course content-management systems (such as Blackboard, WebCT, and Sakai ${ }^{1}$ ), and e-mail, have transformed the ways that faculty teach and interact with students. Among the new technologies are a host of online tools, including Weblogs, wikis, discussion forums, and e-mail lists, that are often bundled into popular content-management systems. While these new technologies offer new opportunities, they may also present challenges for faculty who are less familiar with the differences among the tools and their potential educational uses.

In this article, we focus primarily on the instructional applications of Weblogs (blogs), which offer particular challenges and opportunities for political science faculty who may be considering the use of this tool as part of their courses. ${ }^{2}$ In this regard, our purpose is to provide a basic introduction to blogging and offer some ideas, based on our experiences, for using blogging in the political science classroom.

\section{WHY BLOGS?}

Blogs are Web pages with serialized and regularly updated content, often linking to and commenting upon other blogs, Web sites, or online news. Blogs are organized chronologically and, due to their format, are suited for content that changes frequently

Christopher N. Lawrence is assistant professor of political science in the Department of Social Sciences, Texas A\&M International University, Laredo, Texas. His research interests include legislative politics, public opinion, and voting behavior in advanced industrial democracies, primarily within the United States. He is a contributor to the group blog Outside the Beltway and maintains an individual blog. He used student blogs as part of an introductory American government course at Duke University in the fall of 2005. He can be reached at christopher.lawrence@tamiu.edu.

Michelle L. Dion is assistant professor of political science in the Department of Political Science, McMaster University, Hamilton, Ontario, Canada. Her research explores the political economy of social policy in the developing world. She used a group blog as part of a Georgia Tech study-abroad program at Tec de Monterrey in the summer of 2007. She can be reached at dionm@mcmaster.ca. and links to other online content. These attributes make blogs appropriate for assignments that require reflection and writing in response to timely online resources and news. Though blogs often include tools that allow readers to respond to and comment on their posted articles (posts), the commentary or discussions are usually secondary to the serialized articles, which are central to a blog's purpose and organization. This implies that blogs, by design, are best suited for assignments that require students to write essays in response to other blogs and other online media, such as news articles and video clips published by professional journalists, political campaigns, government officials, and civil society groups.

Faculty should understand that although blogs have a flexible and customizable format, there are often other online technologies that may better serve certain educational or classroom functions. For example, blogs may be less effective for faculty to quickly and easily notify students of class news or assignments because they require students to regularly check a Web site. For dissemination of information to class members, a class e-mail list may still be the more low-tech and efficient alternative. If instructors want students to discuss topics, readings, or assignments online, an online discussion forum would probably be better than a blog since forums are primarily organized by topic rather than date, making it easier for students to find the topic, or "thread," that they are looking for without wading through chronologically organized pages. And though blogs can allow students to comment on each other's writing, they are not particularly well suited for collaborative writing and editing. Wikis are usually a better tool for collaborative writing, study guides, or multiple drafts of essays. ${ }^{3}$

As this brief overview makes clear, new online tools, including Weblogs, may have promise for enhancing teaching, but only to the extent that instructors choose the tools that best fit their educational goals. The rest of this article will specifically address the ways that Weblogs are suited for class use based on our experiences using blogs in classroom assignments. ${ }^{4}$ We begin by providing an overview of the ways that blogs are typically used for political commentary and critical analysis. Then, we explain how many of the characteristics of successful political blogs are related 
to some skills that faculty seek to develop in their students. We then provide a short discussion of additional pedagogical and logistical issues instructors should consider before deciding whether and how to use blogs in their classes, and conclude with a discussion of two potential types of blogging assignments that faculty using blogs for the first time may use as templates for their assignments.

\section{POLITICAL WEBLOGS}

Much as the Internet has had a significant impact on the way we teach, it has also had a dramatic effect on how the public engages in politics and interact with government. ${ }^{5}$ The interactivity afforded by the Internet has transformed the media marketplace from one dominated by a limited number of content providers facing relatively little local competition for consumers, operating as "broadcasters," to a consumer-led market in which readers and viewers can select from a wide variety of media sources originating from all over the globe that suit their personal interests and preferences.

While most early blogs focused on either technology-related issues or were online personal diaries, a number of notable blogs devoted to political commentary were established on the Web in 2001, from a variety of political viewpoints. attracted from commentators across the political spectrum was credited by at least some in the media for helping sustain the controversy and eventually forcing Lott's resignation as Senate majority leader.

Since that controversy, the political blogosphere has exploded and new forms of political blogging have emerged. Markos "Kos" Moulitsas Zúniga and Jerome Armstrong, proprietors of two leading progressive blogs (The Daily Kos and MyDD), pioneered the extensive use of blogs as grassroots organizing tools, with Moulitsas Zúniga transforming his formerly solo-authored blog into a left-wing hub open to hundreds of contributors, while both Moulitsas Zúniga and Armstrong lent their Internet expertise to Democratic campaigns. Right-leaning bloggers have generally met with less success in pursuing this organizational strategy (the most notable conservative exemplar is RedState, which has not seen the same success as The Daily Kos).

Somewhat less dramatically, bloggers from liberal, conservative, and libertarian viewpoints have banded together to form "group blogs" to bring together (usually similar) voices to sustain greater readership and advertising dollars by offering more frequent posting and a "one-stop shop" for political commentary. Other "star" bloggers have been invited to move their content to established media Web sites; liberal blogger Kevin Drum moved

\section{The unique features of blogging have lent themselves particularly well to political commentary. Political blogs tend to combine links to, and excerpts from, mass-media accounts of daily political events with political commentary by their authors, links to other blogs with commentary on these events, and (often, but not always) a comment forum associated with each post for visitors to contribute their own commentary and debate with other visitors or the post's author. They foster dialogue between bloggers and their audience, provide for the summarization and dissemination of political news and events, and help readers to conceptualize the political world.}

The unique features of blogging have lent themselves particularly well to political commentary. Political blogs tend to combine links to, and excerpts from, mass-media accounts of daily political events with political commentary by their authors, links to other blogs with commentary on these events, and (often, but not always) a comment forum associated with each post for visitors to contribute their own commentary and debate with other visitors or the post's author. They foster dialogue between bloggers and their audience, provide for the summarization and dissemination of political news and events, and help readers to conceptualize the political world.

Many political blogs rose to prominence during the aftermath of the 9/11 attacks, the war in Afghanistan, and the lead-up to the conflict in Iraq and became known as "warblogs," to contrast them with the technological or personal blogs, although this term is now generally only applied (largely pejoratively) to blogs that are seen as supportive of the war in Iraq. Interest in blogs in domestic American politics was piqued by the controversy surrounding former Sen. Trent Lott's remarks at the 1ooth birthday celebration of Sen. Strom Thurmond in December 2002; the opprobrium that Lott's remarks regarding Thurmond's 1948 presidential run from CalPundit to the Washington Monthly (and thence to Mother Jones), while the Atlantic attracted bloggers Andrew Sullivan, Matthew Yglesias (now at the Center for American Progress), and Megan McArdle from across the political spectrum. While the traditional "solo" political blog is still around and some remain very popular to this day, such as Glenn Reynolds' Instapundit (which is edited more as a series of pointers to posts by other bloggers rather than as a forum for Reynolds' personal views), group and established-media blogs appear to be the dominant forms of political blogs in terms of advertising revenue, media agenda setting, and mass readership.

\section{USING BLOGS TO DEVELOP STUDENTS' SKILLS}

Regardless of the specific format or sponsorship, however, the best political blogs share some traits we want to impart to and see demonstrated by our students:

1. Critical Reading and Thinking Skills: The best political bloggers are critical consumers of media content. They evaluate the evidence that politicians and pundits bring to bear in support of their conclusions and search for inconsistencies between 
statements by various observers. For example, the controversy over memos alleging President Bush was derelict in his National Guard duties, which ultimately led to Dan Rather's departure from CBS News, would not have come about had bloggers not recognized that a key document in question was apparently produced by computer software unavailable in the early 1970s. Similarly, we often expect students to engage with primary and secondary sources and evaluate their arguments and the evidence supporting them.

2. Political Awareness and Engagement: To effectively blog about what is happening on the national and international scene, political bloggers must be acutely aware of current events and the context in which those events take place, context that may not always be provided in mass-media accounts of the news of the day. The firestorm over Lott's comments at Thurmond's birthday party came about because political bloggers recognized the historical significance of Lott's praise of Thurmond's "Dixiecrat" presidential run; by comparison, although a number of prominent journalists attended the event and filed reports on it, only Thomas Edsall of the Washington Post, who had written extensively about Southern politics in the past, recognized the significance of Lott's comments in his initial reporting.

3. Background Research and "Detective Work": Informed blogging also, at times, requires archival research or other detailed investigation to investigate the veracity of claims by political actors. For example, the controversy over the revelation of former covert CIA officer Valerie Plame's identity as an undercover agent involved competing claims from administration officials, Plame, her husband (former ambassador Joe Wilson), and others, encompassing questions such as the timing when various journalists received information about Plame, the nature and extent of Wilson's efforts to verify or refute intelligence claims that Saddam Hussein's regime had sought nuclear materials in Africa, and the veracity of testimony by administration officials who claimed not to be involved in leaking Plame's identity to various journalists. Efforts to evaluate these claims required bloggers to marshal evidence from a variety of archival sources.

4. Essay Writing: Blogging is inherently a public, written medium of communication. The public nature of blogging may encourage students to communicate more clearly and with greater grammatical correctness (if only to avoid potential ridicule from their classmates and the public at large!). Short-form essay writing is a valuable skill that helps students process and learn new material. Faculty may also find that students are more receptive to a larger number of small writing assignments rather than fewer large ones. Several smaller writing assignments also provide more opportunity for faculty to provide feedback to students that they can use to improve their writing over the duration of a course. Particularly as institutions and accreditors have increasingly emphasized "writing across the curriculum," blogs may be a low-cost way to introduce this dimension even into higher-enrollment courses where traditional writing assignments may be impractical to grade.

5. Reflection: Much of the value of blogging comes about through bloggers' integrating information from various sources into a coherent whole. Xie, Ke, and Sharma (2008) show that blogging can be an effective means to improve students' reflective abilities. In particular, blogging in political science classes may provide students the opportunity to relate concepts and ideas learned in class to current real-world events. For example, in a class on political parties and elections, students could consider how theoretical explanations of political campaigns correspond to current election contests. In an international relations or comparative politics class, students could be asked to analyze a current event from a particular perspective or in relation to concepts learned in class. Even in political theory courses, students could be encouraged to discuss contemporary examples of issues or debates covered in class. Such assignments have the potential to help students understand the real world value or application of their coursework.

The focus of this list is on the skills associated with political blogging-particularly those skills that the technology and blogging culture seem best suited to teach our students. Notice that political discussion and collaborative writing or re-writing are not on this list. While blog technology could be used to develop those skills, it is probably not the most efficient online tool for that 
purpose. ${ }^{6}$ This means that blogging may not be suitable for all classes nor all course objectives. But for those classes that seek to impart the skills above, blogging may be one way to engage students. In table 1 , we propose a few blogs that instructors may wish to use as models for students.

Getting students to successfully become bloggers may also require faculty to encourage students to alter the way they consume media content. Rather than searching newspaper Web sites and Google News to trawl for topics, the most successful bloggers read a wide variety of articles in various news outlets and pick out stories they find to be interesting or under-discussed. In other words, rather than asking students to search for stories to blog about a particular topic or issue, instructors are likely to be more successful in getting students to emulate the best bloggers if they encourage students to pursue a more holistic approach to reading the news and other blogs. dents. This includes criteria such as the number of posts expected, their word length, any requirements for links to external sites (massmedia articles and other references), and whether (and, if so, how often) students are expected to post comments on or otherwise acknowledge posts by their classmates. Instructors should also make clear how posts will be evaluated-will students be evaluated on dimensions such as style, grammar, the quantity and/or quality of their links and research, and the originality of their insights?

Fourth, in addition to providing students with clear instructions and evaluation criteria, faculty would be well served by providing students with examples of the types of posts and blogging they should emulate. This may require a short introduction to political blogs: what they are, how they are different from other types of blogs, and what purpose they serve. Faculty can easily lead by example and choose to blog with students, at least during the early weeks of a semester. Another approach might be to pro-

\section{The best political bloggers are critical consumers of media content. They evaluate the evidence that politicians and pundits bring to bear in support of their conclusions and search for inconsistencies between statements by various observers.}

Of course, many of the above goals can be achieved successfully through other means. We suggest that faculty consider blogs to be another, complementary tool for engaging students in further reflection and burrowing deeper into topics presented in class, rather than a substitute for other teaching approaches. Given students' demonstrated interest in social media, blogs appear to be a helpful way to engage students on their home turf and draw them into the more traditional dimensions of our courses.

\section{BRINGING POLITICAL BLOGS INTO THE CLASSROOM}

To ensure that blogging exercises meet their course objectives, instructors should carefully consider several issues in the design of their course and blog assignments. First, they should evaluate the role of blogging in the context of the whole course. Will it be a substitute for other writing? How much blogging will be expected of students, and how will that effort be reflected in students' course grades?7 We would suggest that instructors relate blog assignments to specific units of their courses and make reference to students' posts in class, to ensure students make the connection between blogging and the broader course.

Second, instructors should decide whether they want students to maintain individual blogs or belong to a group blog, where the group could be subsets of a class or the entire class. Do they want students to blog in isolation or read each others' posts regularly? In larger classes, would it make sense to divide the class into topical groups that would follow a particular issue or country over the course of the semester? In practice, individual blogs are likely to require students and the instructor to visit multiple sites to follow or comment upon posts. In contrast, a group or class blog centralizes posts onto one site, making it easier for class members to follow updates and even write follow-up posts related to earlier posts or discussions. Most blogging tools allow site visitors to follow or read posts by particular authors, making it easier to evaluate a set of posts by one author.

Third, as with any new learning or evaluation tool, instructors need to provide very clear instructions and expectations for stu- vide students with links to exemplar posts on blogs related to the course content, perhaps having students comment on or critique an exemplar post as part of their first assignment.

\section{EXAMPLE ASSIGNMENTS}

Within the objectives and recommendations above, there are a plethora of potential approaches that instructors might pursue in blogging assignments. Here are a couple of broad ideas that we have used and believe are fairly straightforward for faculty to build on in their first foray into using blogs:

1. Response to News Clippings: The widespread availability of newspapers on the Internet, coupled with blogging tools, permits instructors to go beyond the traditional "diary of news clippings" approach to engaging students in real-world material related to class. A very basic model of this approach has been pursued by one of the coauthors of this article by having students in an introductory American government class track and comment on political news in the U.S. state or territory of their choice. The primary challenge for faculty with this type of assignment is to encourage students to move beyond superficial commentary to relate the political news to themes discussed in class; for example, teaching students to respond to reports of a state opinion poll on same-sex marriage with commentary on public opinion (such as the question wording, sampling approach, and the like) or civil liberties and rights (perhaps by relating the effort to obtain recognition for same-sex marriage to the challenges faced by mixed-race couples prior to Loving v. Virginia) rather than simply offering a response based on their own personal views of the issue.

Similar assignments would be easy to introduce in a variety of courses, such as country or area-focused courses in comparative politics, although language barriers might be a challenge when having students blog about sub-national politics in nonEnglish-speaking nations depending on student language skills. Faculty might also choose to assign themes based on class topics 
rather than, or in addition to, areas to students; in fields such as international relations and political theory, or certain upperdivision courses in American and comparative politics, themebased blogs may be the more viable approach.

2. Experiential Blogging: Students who are participating in studyabroad programs or field research such as internships often are asked to produce a final report at the end of the experience; given the nature of student procrastination and recall, however, these reports may be rushed and incomplete. Leaders of these programs may instead want to have students report on their experiences, at least partially, while they are experiencing them, and blogs are an excellent tool for doing so. One of the coauthors successfully used a group blog to this effect as part of a summer study-abroad program in Mexico, and it would be easy to generalize this approach to other settings such as Washington semester programs, state capital internships, and other off-campus group or individual experiential learning programs. This type of blog, in addition to being a pedagogical tool, might also have promotional benefits for encouraging future student participation in the program. Faculty might consider combining the student blogs with a more traditional summary paper to capture both the experiential and reflective dimensions of the off-campus study experience.

\section{FINAL CONSIDERATIONS}

Whatever approach faculty decide to take, they should be mindful of the more general suggestions discussed earlier; in our experience, setting clear and consistent expectations of students is probably the key to a successful class blogging assignment, no matter what format is used.

As is the case for most innovations in course design, introducing blogging into a political science course requires careful thought and consideration. Taking advantage of the unique features of the medium can substantially enrich a wide variety of courses, so long as faculty invest sufficient time and effort into ensuring-like all assignments-that it is well connected with the goals of the course and will enhance student learning outcomes. We hope this advice will help faculty who are considering using this growing medium in meeting that goal. $\mathrm{E}$

\section{NOTES}

Christopher's contributions to the article are based, in part, on a presentation he made at the 2006 Southern Political Science Association meeting, in Atlanta, GA; he would like to thank the participants in that panel, chaired by Steven L. Taylor, for their helpful comments. Michelle's contributions are based on a workshop she led at the 20o8 APSA TLC in San Jose, CA. We also thank M. Zak Taylor and Mitchell Brown for their helpful comments on an earlier draft of this article.

1. Sakai (sakaiproject.org) is an open-source course content management system.

2. There are also substantial non-instructional applications of blogs at universities and colleges; for example, many colleges' admissions offices use student blogs to recruit prospective students and give a window into student life, while a number of institutions (including Stanford, Harvard, and Georgia Tech) have established blog sites for faculty to promote their research expertise to the broader public.

3. Richardson (2006) provides a more extensive overview of the strengths and weaknesses of various online technologies as pedagogical tools, albeit emphasizing applications in primary and secondary education; Bryant (2006) provides a briefer overview that also encompasses instant messaging, Voice over IP, and social bookmarking tools.

4. We leave to others the question of the effectiveness of different uses of Weblogs. Our interest is instead to provide an introduction to the blog format and how it may be used in teaching.

5. For a more detailed overview, see Drezner and Farrell (2008a, 2008b); in addition, McKenna and Pole (2008) discuss how the typical political blog operates on a daily basis.

6. For political discussion, we would recommend an online discussion board or forum, and for collaborative writing, a wiki would be more appropriate.

7. Instructors will want to carefully consider the number and length of posts expected of students, both to ensure students are not overly burdened and to make sure the faculty member can provide timely and meaningful feedback.

8. Theoretically students could also use one of the popular social-networking sites such as LiveJournal, MySpace, or Facebook to produce blogs, but it would probably be undesirable to combine students' "personal" online presence with that required as part of a course.

\section{REF E R E N C E S}

Bryant, Todd. 2006. "Social Software in Academia." Educause Quarterly 29 (2): 61-64.

Drezner, Daniel W., and Henry Farrell. 2008a. "Introduction: Blogs, Politics, and Power: A Special Issue of Public Choice." Public Choice 134 (1-2): 1-13.

$$
\text { 2008b. "The Power and Politics of Blogs." Public Choice } 134 \text { (1-2): 15-30. }
$$

McKenna, Laura, and Antoinette Pole. 2008. "What Do Bloggers Do? An Average Day on an Average Political Blog." Public Choice 134 (1-2): 97-108.

Richardson, Will. 2006. Blogs, Wikis, Podcasts, and Other Powerful Web Tools for Classrooms. Thousand Oaks, CA.: Corwin Press.

Xie, Ying, Fengfeng Ke, and Priya Sharma. 2008. "The Effect of Peer Feedback for Blogging on College Students' Reflective Learning Processes.” Internet and Higher Education 11: 18-25.

\section{APPENDIX: Features of Popular Blog Tools}

Many tools are available for establishing and maintaining blogs. Popular coursemanagement systems such as Blackboard, Moodle, ANGEL, and Sakai include blogging modules that work within a particular course. While such tools may make blogging easier to administer and evaluate, to the extent that they are in a "walled garden," they will isolate the class blog from the broader blogosphere and may create the sense for students that blogging is more like the traditional "journal" assignment than a means to interact with the world beyond the classroom. Blogging tools are also available for producing blogs that will be accessible to the general public over the Internet; popular "turn-key" platforms that do not require end-user installation include Google's Blogspot service, Sixapart's TypePad, WordPress.com, and Edublogs, each of which are built on popular self-hosted solutions (Blogger, MovableType, and WordPress) that may also be viable solutions if your institution has instructional technology support staff who can help faculty set up blogs using one or more of those platforms. ${ }^{8}$ Considerations for the choice of blogging tool include ease of setup and use, flexibility to adapt to various course demands, convenience of assessment, the availability of institutional licensing and technical support for tools, privacy concerns, and maintenance requirements. These features are summarized in table 2. 
Table 2

Features of Common Blog Platforms for Classroom Use

\begin{tabular}{|c|c|c|c|c|c|c|c|c|}
\hline \multirow[b]{2}{*}{ FEATURE } & \multicolumn{4}{|c|}{ BLOGGING WITHIN COURSE-MANAGEMENT SYSTEMS } & \multicolumn{4}{|c|}{ STAND-ALONE BLOGGING SITES } \\
\hline & Blackboard & Moodle & SakaiProject $^{1}$ & ANGEL & Blogspot & TypePad & WordPress.com & Edublogs \\
\hline Privacy from public Internet & $\begin{array}{l}\text { Invisible to non- } \\
\text { course members }\end{array}$ & $\begin{array}{l}\text { Invisible to non- } \\
\text { course members }\end{array}$ & $\begin{array}{l}\text { Password } \\
\text { protection of } \\
\text { entries, blog }\end{array}$ & $\begin{array}{l}\text { Invisible to non- } \\
\text { course members }\end{array}$ & $\begin{array}{l}\text { Password } \\
\text { protection } \\
\text { of blog }\end{array}$ & $\begin{array}{l}\text { Password } \\
\text { protection of } \\
\text { entries, blog }\end{array}$ & $\begin{array}{l}\text { Password } \\
\text { protection of } \\
\text { entries, blog }\end{array}$ & $\begin{array}{l}\text { Can prevent search } \\
\text { engines from indexing } \\
\text { blog; additional options } \\
\text { with upgrade }\end{array}$ \\
\hline Ease of setup & Easy & Easy & Easy & Easy & Easy & Medium & Medium & Medium \\
\hline Categories/tags & No & Yes & No & Yes & No & Yes & Yes & Yes \\
\hline Course blogs & Yes & $\begin{array}{l}\text { Sort of, via "course } \\
\text { tags" }\end{array}$ & Yes & Yes & Yes & Yes & Yes & Yes \\
\hline Group blogs & No & $\begin{array}{l}\text { Sort of, via "course } \\
\text { tags" }\end{array}$ & Yes & Yes & Yes & Yes & Yes & Yes \\
\hline Individual blogs & No & Yes & Yes & Yes & Yes & Yes & Yes & Yes \\
\hline $\begin{array}{l}\text { Per-entry grading tool tied } \\
\text { to grade book }\end{array}$ & Yes & No & No & Yes & No & No & No & No \\
\hline Plagiarism detection & $\begin{array}{l}\text { Included (with Safe- } \\
\text { Assign module) }\end{array}$ & Manual only & Manual only & Manual only & Manual only & Manual only & Manual only & Manual only \\
\hline Pricing $^{2}$ & $\begin{array}{l}\text { Included with Black- } \\
\text { Board site license }\end{array}$ & Free & Free & $\begin{array}{l}\text { Included with ANGEL } \\
\text { site license }\end{array}$ & $\begin{array}{l}\text { Free, private } \\
\text { blogs limited } \\
\text { to } 100 \text { users }\end{array}$ & $\begin{array}{l}\text { Minimum viable } \\
\text { plan: } \$ 14.95 / \text { month, } \\
\text { unlimited blogs and } \\
\text { users, } 1 \text { GB space }\end{array}$ & $\begin{array}{l}\text { Free up to } 3 G B \\
\text { space; private } \\
\text { blogs limited to } \\
35 \text { users }\end{array}$ & $\begin{array}{l}\text { Free up to } 20 \mathrm{MB} \text { space; } \\
\$ 14.95 / 3 \mathrm{mo} \text {. or } \\
39.95 / 12 \mathrm{mo} \text {. per } \\
\text { blog buys } 5 \mathrm{~GB} \text { and } \\
\text { enhanced features }\end{array}$ \\
\hline
\end{tabular}

Notes

1. This open-source project is often rebranded by universities and thus may have a different name.

2. A "viable plan" includes access to create multiple blogs and have multiple users per blog. 